
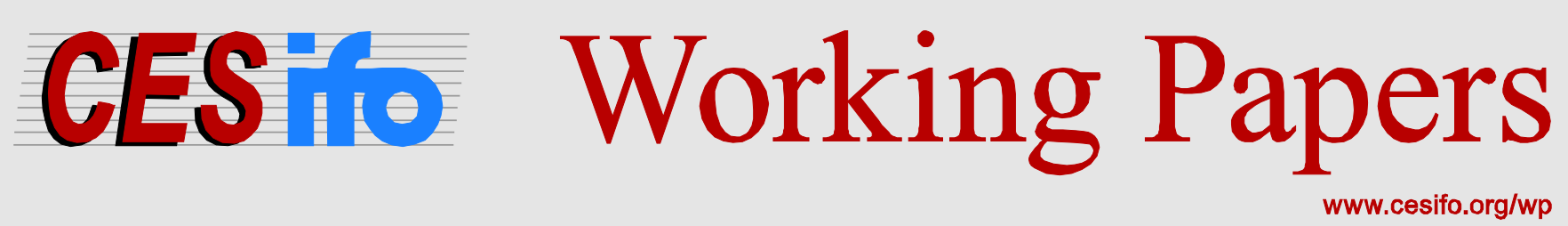

\title{
Decentralized Road Investment and Pricing in a Monocentric, Multi-Jurisdictional City: Efficiency with Spillovers
}

\author{
Jan K. Brueckner \\ CESIFO WORKING PAPER No. 4473 \\ CATEgory 1: Public FinANCE \\ NOVEMBER 2013 \\ An electronic version of the paper may be downloaded \\ - from the SSRN website: \\ - from the RePEc website: \\ - from the CESifo website: \\ WwW.SSRN.com \\ www.RePEc.org \\ www.CESifo-group.org/wp
}

\section{CESifo}




\title{
Decentralized Road Investment and Pricing in a Monocentric, Multi-Jurisdictional City: Efficiency with Spillovers
}

\begin{abstract}
This paper shows that the inefficiency of fiscal decentralization in the presence of spillovers, a main tenet of the decentralization literature, is overturned in a particular transportation context. In a monocentric city where road (bridge) capacity is financed by budget-balancing user fees, decentralized capacity choices (made by individual zones within the city) generate the social optimum despite the presence of spillovers. This conclusion is closely tied to the famous self-financing theorem of transportation economics.
\end{abstract}

JEL-Code: H700.

Keywords: spillovers, congestion, self-financing theorem.

Jan K. Brueckner

Department of Economics

University of California, Irvine

3151 Social Science Plaza

USA - Irvine, CA 92697

jkbrueck@uci.edu

September 2013 


\section{Decentralized Road Investment and Pricing in a Monocentric, Multi-Jurisdictional City: Efficiency with Spillovers}

by

Jan K. Brueckner*

\section{Introduction}

Whether fiscal decentralization is optimal depends on the presence of interjurisdictional spillovers in policy decisions. As argued by Oates (1972), local policy choices, which beneficially allow fulfillment of local preferences, are nevertheless inefficient when significant public-sector spillovers exist. The reason is that the external benefits (or costs) of a policy will be ignored by local decision-makers. Under these circumstances, centralization of public-sector decisions may be desirable. This argument, which was recently reformulated in a precise fashion by Besley and Coate (2003), ${ }^{1}$ helped to spawn a vast literature on the pros and cons of decentralization.

Only recently has this literature turned to the question of decentralization of transportation investment and pricing decisions. Westin et al. (2012), DeBorger and Proost (2013), and Ferguson (2013) study this question using different types of models, reaching a variety of conclusions. The present paper adds to this nascent branch of the literature by analyzing decentralized road investment and pricing in a monocentric city, adapting the framework of Brueckner and Helsley (2011). ${ }^{2}$ The city is composed of separate jurisdictions, called "zones". These zones are connected by a sequence of congestible bridges, across which the city's residents commute to reach their jobs in the CBD. Bridges are locally controlled, with capacity and pricing on a bridge determined by the adjacent zone. A spillover exists in bridge-capacity choices, which generate external benefits, and through the congestion phenomenon, which

\footnotetext{
* I thank Jinwon Kim, Kangoh Lee, Ken Small, David Wildasin, and especially Sofia Franco for comments and suggestions. Any errors, however, are mine.

1 Their analysis was offered as a prelude to development of a different model with features at variance with the Oates tradition.

2 Road congestion in monocentric cities is the focus of a long literature, which includes (in addition to Brueckner and Helsley (2011)) papers by Kanemoto (1977), Pines and Sadka (1985), Wheaton (1998), Anas and Pines (2008). However, none of these papers considers decentralized road investment and pricing decisions.
} 
involves the usual externalities. The remarkable conclusion of the analysis is that, despite these spillovers, decentralized investment and pricing is efficient, leading to an urban equilibrium that coincides with the social optimum. ${ }^{3}$

To grasp this conclusion, consider Figure 1, which shows a map of the city, extending the setup used by Brueckner and Helsley (2011). The central zone at the left contains the CBD along with residential land, while the "midcity" and suburban zones lie to the right. The midcity bridge, which is controlled by the midcity zone, connects that zone to the center, while the suburban bridge (again controlled locally) connects the suburbs to the midcity zone. Suburban residents must cross both bridges to reach the CBD, while midcity residents need only cross their own bridge (central residents are not bridge users). Intrazone travel costs are zero, so that the only commuting costs are incurred on the congested bridges. Travel demand is completely inelastic, so that bridge traffic levels are influenced only by the endogenous distribution of the population across the city's zones.

Bridge capacity is financed by user charges. In addition, capacity is produced with constant returns, and bridge congestion is homogenous of degree zero in traffic volume and capacity, conditions that yield the famous self-financing theorem of transportation economics (i.e., congestion tolls exactly cover the cost of an optimal-size road or bridge; see Small and Verhoef (2007)). The governments of the midcity and suburban zones choose their individual bridge capacities to maximize resident utilities, and the result is an efficient equilibrium, which yields an optimal distribution of population across the city's zones and optimal land consumption levels. This outcome is surprising at first because spillovers are present: the midcity's capacity choice affects congestion on its bridge and thus the travel costs of suburban residents; midcity and suburban commuters impose congestion costs on one another on the midcity bridge, and suburban residents congest one another on the suburban bridge. These latter spillovers are properly addressed by congestion tolls, while the capacity spillover (which tends to make the chosen midcity bridge too small) would appear to require a different remedy.

The use of budget-balancing user fees simultaneously addresses both problems. Because the

\footnotetext{
${ }^{3}$ Using a tax competition framework with transboundary pollution, Ogawa and Wildasin (2009) provide another example where decentralized policy choices are efficient in a situation with spillovers.
} 
midcity fees are paid by both midcity and suburban commuters, capacity costs for the midcity bridge are shared with outsiders, encouraging the zone's residents to expand its size, perfectly counteracting the omission of suburban benefits in their capacity decision. In addition, under the conditions of the self-financing theorem, the user fees charged on the two bridges end up functioning as optimal congestion tolls, correcting the congestion spillovers. In other words, since the capacity costs of an optimal-size bridge are just covered by the revenue from an optimal toll, and since user-fee revenue equals these costs, the level of the user fee matches that of the optimal toll.

Thus, as a result of the confluence of these disparate factors, decentralized decisions made by individual local governments are efficient in a transportation context despite the existence of spillovers, providing a notable exception to received wisdom regarding decentralization's desirability. While this finding is new in a monocentric-city setting, DeBorger and Proost (2013) also derived the same type of result in a model with similar features but without an explicit spatial structure and land market (zone residents in their model take trips into other zones, creating congestion). ${ }^{4}$ Nevertheless, given the importance of the efficiency finding, its demonstration in a variety of contexts is worthwhile.

The plan of the paper is as follows. Section 2 develops the model and derives the main efficiency result. Section 3 shows how relaxing the key assumptions of the model overturns efficiency. Section 4 considers centralized decisions, and section 5 offers conclusions.

\section{Analysis}

The variables in the model are as follows. Individual land consumption is denoted $q$, with consumption in the suburban, midcity, and central zones denoted by $q_{s}, q_{m}$, and $q_{c}$. Land's opportunity cost (the agricultural rent) equals $\bar{r}$. The nonland composite good, which is numeraire, is denoted $e$, and consumption levels in the three zones are given by $e_{i}, i=s, m, c$. To simplify the exposition, preferences are assumed to take the quasi-linear form $e+V(q)$, where $V^{\prime}>0, V^{\prime \prime}<0$. The paper's main results continue to hold with a general specification

\footnotetext{
${ }^{4}$ The present work was inspired by DeBorger's presentation of that coauthored paper in a conference setting, which made clear the usefulness of analyzing decentralization in a transportation context. My later, fuller reading of their paper showed that the authors had already derived a result on the efficiency of decentralization in a balanced-budget setting, although as part of a much broader analysis.
} 
of preferences. The populations of the three zones are $n_{i}, i=s, m, c$, and they must sum to the city's fixed overall population $N$, so that

$$
n_{s}+n_{m}+n_{c}=N \text {. }
$$

The capacities of the suburban and midcity bridges are denoted by $k_{s}$ and $k_{m}$. The costs of providing these capacities are given by $B\left(k_{i}\right), i=s, m$, where $B^{\prime}>0$. With constant returns to scale, $B^{\prime \prime} \equiv 0$, while $B^{\prime \prime}>(<) 0$ holds under decreasing (increasing) returns. The time cost of crossing a bridge depends on the level of congestion, which is determined by the traffic volume and the bridge's capacity. ${ }^{5}$ With the traffic volume on the suburban bridge equal to $n_{s}$, the time cost of crossing this bridge is $T\left(n_{s}, k_{s}\right)$, where $T$ 's partial derivatives satisfy $T_{1}>0, T_{2}<0$. With traffic on the midcity bridge equal to $n_{s}+n_{m}$, the time cost of crossing it equals $T\left(n_{s}+n_{m}, k_{m}\right)$. Under the conditions of the self-financing theorem, $T$ is homogeneous of degree zero, being a function only of the volume/capacity ratio.

Note that these time-cost expressions indicate the presence of congestion spillovers across zones. In other words, the cost incurred by the $n_{m}$ midcity residents in crossing their bridge depends on the number of suburban commuters using it. In addition, a suburban resident's cost of crossing the bridge depends on the number of midcity residents using it. By contrast, interzone spillovers are not present on the suburban bridge, although suburban residents congest one another in using it (an intra-zone spillover). Finally, travel costs within each zone are zero.

\subsection{The social optimum}

The planner's goal is to minimize the city's resource consumption while generating a fixed common utility level $u$ for the residents in each of the zones. Since it is inefficient to leave vacant land inside the city, the central and midcity zones will be fully occupied, with vacant land found only in the suburban zone. Normalizing the individual land areas of these two zones to 1 , the constraints

$$
n_{c} q_{c}=1, \quad n_{m} q_{m}=1
$$

\footnotetext{
5 The time used in commuting is assumed to reduce work hours and output, thus yielding a pecuniary cost.
} 
must be satisfied. Imposing these two constraints, the utility constraints, and the overall population constraint, the Lagrangean expression for the planner's problem is

$$
\begin{aligned}
n_{s} e_{s}+n_{m} e_{m}+n_{c} e_{c}+\bar{r}\left(n_{c} q_{c}\right. & \left.+n_{m} q_{m}+n_{s} q_{s}\right)+n_{s} T\left(n_{s}, k_{s}\right)+\left(n_{s}+n_{m}\right) T\left(n_{s}+n_{m}, k_{m}\right) \\
+B\left(k_{s}\right)+B\left(k_{m}\right) & +\sum_{i=s, m, c} \lambda_{i}\left(e_{i}+V\left(q_{i}\right)-u\right)+\gamma\left(n_{s}+n_{m}+n_{c}-N\right) \\
& +\sum_{i=m, c} \theta_{i}\left(n_{i} q_{i}-1\right)
\end{aligned}
$$

The terms up to the first summation sign in (1) capture total resource consumption, which equals total consumption of $e$, plus the opportunity cost of the urbanized land, plus bridge crossing costs, plus the cost of bridge capacities. The various constraints, with Lagrange multipliers appended, appear in the remaining lines of (3).

Differentiating (3) with respect to $e_{i}$ yields $n_{i}=\lambda_{i}, i=s, m, c$. Using these equalities and differentiating (1) with respect to $q_{i}, i=s, m, c$, yields the first-order conditions

$$
\begin{aligned}
V^{\prime}\left(q_{s}\right) & =\bar{r} \\
V^{\prime}\left(q_{i}\right) & =\bar{r}+\theta_{i}, \quad i=m, c .
\end{aligned}
$$

These conditions equate the marginal utility of land consumption to the shadow price of land in a zone, with the suburban shadow price equal to land's opportunity cost $\bar{r}$ and the $\theta$ 's giving price premia in the inner zones.

The first-order conditions for bridge capacities, $k_{i}, i=s, m$ are

$$
\begin{aligned}
B^{\prime}\left(k_{s}\right)+n_{s} T_{2}\left(n_{s}, k_{s}\right) & =0 \\
B^{\prime}\left(k_{m}\right)+\left(n_{s}+n_{m}\right) T_{2}\left(n_{s}+n_{m}, k_{m}\right) & =0
\end{aligned}
$$

which indicate that the total time-cost savings from an increase in capacity (the negative of the second term) equals marginal capacity cost. 
The first-order conditions for $n_{c}$ and $n_{m}$ are

$$
\begin{gathered}
e_{c}+\left(\bar{r}+\theta_{c}\right) q_{c}=-\gamma \\
e_{m}+\left(\bar{r}+\theta_{m}\right) q_{m}+T\left(n_{s}+n_{m}, k_{m}\right)+\left(n_{s}+n_{m}\right) T_{1}\left(n_{s}+n_{m}, k_{m}\right)=-\gamma
\end{gathered}
$$

These conditions say that the resource costs of adding an extra person to the central and midcity zones should be the same and equal to $-\gamma$. These costs include the individual's $e$ consumption, the cost of her land (evaluated at the shadow price), and the extra commuting cost generated by her presence. While this cost is zero for someone added to the center, a person added to the midcity zone incurs her own cost $(T(\cdot)$ in $(9))$ while raising time costs by $T_{1}$ for each of the other $n_{s}+n_{m}$ commuters on the midcity bridge (aggregating yields the last term in (9)).

Eqs. (8) and (9) can be combined by substituting $e_{i}=u-V\left(q_{i}\right), i=s, m$, into the LHS expressions and then equating these expressions to eliminate $\gamma$. Multiplying through by -1 , the result is

$$
V\left(q_{c}\right)-\left(\bar{r}+\theta_{c}\right) q_{c}=V\left(q_{m}\right)-\left(\bar{r}+\theta_{m}\right) q_{m}-\left(n_{s}+n_{m}\right) T_{1}\left(n_{s}+n_{m}, k_{m}\right)-T\left(n_{s}+n_{m}, k_{m}\right) .
$$

The first-order condition for $n_{s}$ is $e_{s}+\bar{r} q_{s}+T^{s}+n_{s} T_{1}^{s}+T^{m}+\left(n_{s}+n_{m}\right) T_{1}^{m}=-\gamma$, where the $T$ superscripts indicate that the functions are evaluated in zones $m$ and $s$. The LHS expression gives the cost of adding a resident to the suburban zone, which generates time and congestion costs on both bridges. This condition is transformed by eliminating $e_{s}$, multiplying through by -1 , and setting the result equal to the RHS of (10) (which equals $\gamma-u$ ). The terms $-T^{m}-\left(n_{s}+n_{m}\right) T_{1}^{m}$ and $u$ are common to both expressions and thus cancel, yielding the condition

$$
V\left(q_{m}\right)-\left(\bar{r}+\theta_{m}\right) q_{m}=V\left(q_{s}\right)-\bar{r} q_{s}-n_{s} T_{1}\left(n_{s}, k_{s}\right)-T\left(n_{s}, k_{s}\right) .
$$

Satisfaction of conditions (10) and (11) implies that the resource costs of adding a person to the central, midcity or suburban zones are all equal. 
The ten conditions consisting of (1)-(2), (4)-(7) and (10)-(11) determine the socially optimal values of the ten variables $q_{c}, q_{m}, q_{s}, n_{s}, n_{m}, n_{c}, k_{s}, k_{m}, \theta_{m}, \theta_{c}$. The $e$ consumption levels in the three zones can be recovered from the utility constraints. Note that the only effect of a change in the parametric utility level $u$ is to change the $e$ values. Thus, unlike in the case where income effects are present, the values of the ten variables above are the same in all social optima.

\subsection{The decentralized equilibrium}

Turning to a characterization of the decentralized equilibrium, the urban residents earn a maximal income of $y$ from employment at the CBD, which is reduced by the loss of work time from congested bridge crossings. As explained in the introduction, each zone is a separate jurisdiction, with the governments of the midcity and suburban zones having the power to determine the capacities of their respective bridges. In addition, the two zones are able to levy user fees on commuters crossing their bridges. Users of the suburban bridge consist only of the zone's residents, so that suburban user-fee revenue is internal to that zone. But users of the midcity bridge consist of both suburban and midcity residents, so that some of the midcity's user-fee revenue comes from suburban residents. Finally, each jurisdiction must satisfy a balanced-budget requirement, with user-fee revenue exactly covering the capacity cost of its bridge.

Using these assumptions, and letting $r_{m}$ denote midcity land rent, the budget constraint of a midcity resident is

$$
e_{m}=y-r_{m} q_{m}-\frac{B\left(k_{m}\right)}{n_{s}+n_{m}}-T\left(n_{s}+n_{m}, k_{m}\right)
$$

where the third term on the RHS is the budget-balancing user fee (capacity cost divided by the number of users of the midcity bridge). The suburban resident's budget constraint is

$$
e_{s}=y-\bar{r} q_{s}-\frac{B\left(k_{s}\right)}{n_{s}}-\frac{B\left(k_{m}\right)}{n_{s}+n_{m}}-T\left(n_{s}, k_{s}\right)-T\left(n_{s}+n_{m}, k_{m}\right)
$$

Note that a suburban resident incurs time costs on two bridges and pays user fees on each one (the third term on the RHS of (13) is the suburban fee). Note also that the land rent paid by 
this resident equals $\bar{r}$, the agricultural value. Finally, since residents of the central zone incur no commuting cost, their budget contraint is simply $e_{c}=y-r_{c} q_{c}$, where $r_{c}$ denotes central land rent.

Zone residents choose land consumption levels to maximize their utilities, $e_{i}+V\left(q_{i}\right), i=$ $s, m, c$. Using the budget constraints, the first-order conditions are

$$
\begin{aligned}
V^{\prime}\left(q_{s}\right) & =\bar{r} \\
V^{\prime}\left(q_{i}\right) & =r_{i}, \quad i=m, c .
\end{aligned}
$$

In addition, zone governments, acting on behalf of the suburban and midcity residents, choose the capacities of their bridges. In doing so, each government views the other zone's capacity choice and the zone populations as parametric, even though these populations are ultimately determined by the capacity choices. Using the budget contraints (12) and (13), the resulting first-order conditions for $k_{s}$ and $k_{m}$ are

$$
\begin{aligned}
\frac{B^{\prime}\left(k_{s}\right)}{n_{s}}+T_{2}\left(n_{s}, k_{s}\right) & =0 \\
\frac{B^{\prime}\left(k_{m}\right)}{n_{s}+n_{m}}+T_{2}\left(n_{s}+n_{m}, k_{m}\right) & =0 .
\end{aligned}
$$

These conditions state that the marginal increase in the user fee due to a capacity expansion equals the resulting saving in individual time cost. Conditions (16) and (17) are equivalent to the planning conditions (6) and (7), resulting from division of each planning condition by bridge traffic $\left(n_{s}\right.$ or $\left.n_{s}+n_{c}\right)$.

As usual in urban models, additional equilbrium conditions require equalization of utilities across zones. In other words, $e_{c}+V\left(q_{c}\right)=e_{m}+V\left(q_{m}\right)=e_{s}+V\left(q_{s}\right)$ must hold. Using the budget constraints to eliminate the $e$ 's in the first equality and cancelling the $y$ 's that appear on both sides, the equality requires

$$
V\left(q_{c}\right)-r_{c} q_{c}=V\left(q_{m}\right)-r_{m} q_{m}-\frac{B\left(k_{m}\right)}{n_{s}+n_{m}}-T\left(n_{s}+n_{m}, k_{m}\right)
$$


Turning to the second of the previous equalities, the budget contraints are again used to eliminate the $e$ 's, and both the common $y$ 's and the common terms $B\left(k_{m}\right) /\left(n_{s}+n_{m}\right)+T^{m}$ are cancelled (see (12) and (13)), yielding

$$
V\left(q_{m}\right)-r_{m} q_{m}=V\left(q_{s}\right)-\bar{r} q_{s}-\frac{B\left(k_{s}\right)}{n_{s}}-T\left(n_{s}, k_{s}\right)
$$

The equilibrium values of $q_{c}, q_{m}, q_{s}, n_{s}, n_{m}, n_{c}, k_{s}, k_{m}, r_{m}, r_{c}$ are determined by ten equilibrium conditions: the population and land area constraints in (1) and (2), the first-order conditions (14)-(17), and the utility-equalization conditions (18)-(19). Recognizing that the land shadow prices $\bar{r}+\theta_{c}$ and $\bar{r}+\theta_{m}$ and the rents $r_{c}$ and $r_{m}$ are equivalent, the equilibrium and optimality conditions can be compared.

\subsection{Comparing the equilibrium and optimum}

The constraints (1) and (2) are common to the equilibrium and optimality conditions, and the first-order conditions for the $q$ 's are also the same in the two cases. As noted above, the capacity-choice conditions (16) and (17) are also the same as the corresponding planning conditions, and this equivalence indicates that the potential distortion from the capacity spillover associated with the midcity bridge is corrected in the equilibrium. To see how, recall that the distortion arises because midcity residents have no incentive to consider the benefits to suburban residents in choosing their bridge capacity. However, since user-fee financing means that the midcity bridge is partly paid for by outsiders (suburban residents), midcity decision-

makers are encouraged to expand its capacity. This incentive exactly cancels the tendency to underprovide capacity due to the spillover, yielding an optimal outcome. Thus, reliance on user fees is crucial in generating an optimal bridge capacity.

In comparing the planning and equilibrium conditions, the remaining comparison is between the population-allocation conditions (10)-(11) and the equal-utility conditions (18)-(19). The conditions are different, with the term $\left(n_{s}+n_{m}\right) T_{1}^{m}$ in (10) replaced by $B\left(k_{m}\right) /\left(n_{s}+n_{m}\right)$ in (18) and an analogous difference seen in (11) and (19). However, under the assumptions of the self-financing theorem, the conditions are the same. These assumptions are constant returns in provision of bridge capacity, implying $B\left(k_{m}\right)=\beta k_{m}$, and zero-degree homogeneity of $T$, which 
implies $\left(n_{m}+n_{s}\right) T_{1}^{m}+k_{m} T_{2}^{m}=0$ or $T_{2}^{m}=-\left[\left(n_{s}+n_{m}\right) / k_{m}\right] T_{1}^{m}$. Using this latter relationship to replace $T_{2}^{m}$ in $(7)$ and noting $B^{\prime}=\beta$, the condition becomes, after rearrangement,

$$
\frac{B\left(k_{m}\right)}{n_{s}+n_{m}} \equiv \frac{\beta k_{m}}{n_{s}+n_{m}}=\left(n_{s}+n_{m}\right) T_{1}\left(n_{s}+n_{m}, k_{m}\right)
$$

Therefore, $\left(n_{s}+n_{m}\right) T_{1}^{m}$ in the planning condition (10) can be replaced by $B\left(k_{m}\right) /\left(n_{s}+\right.$ $n_{m}$ ), making that condition the same as the equilibrium condition (18). Thus, when capacity is chosen optimally, the midcity user fee equals the optimal congestion toll, given by the expression on the RHS that captures the congestion damage from an extra midcity-bridge commuter. For the city's population to be optimally distributed, these commuters must face such a toll. The same argument shows that the suburban bridge's user fee also equals the optimal toll, establishing that (11) and (19) are the same and thus that the equilibrium and social optimum coincide. Note that, after multiplying through by $n_{s}+n_{m}$, (20) says that capacity cost equals congestion toll-revenue (the self-financing theorem).

Thus, by relying on budget-balancing user fees, the midcity residents choose their bridge capacity in a socially optimal fashion despite the presence of a spillover. Given the self-financing theorem, the user fee associated with this optimal capacity then coincides with the optimal congestion toll, ensuring a proper distribution of the population across zones. Note that with a capacity spillover absent, the only distortion affecting suburban choices is congestion, which is handled correctly by the optimal toll.

Summarizing yields

Proposition 1. Suppose that the conditions of the self-financing theorem (constant returns in provision of capacity and zero-degree homogeneity of congestion costs) are satisfied. Then, provided that financing relies on budget-balancing user fees, decentralized choice of road (bridge) capacities in a multijurisdictional city with spillovers leads to an efficient equilibrium.

\section{Relaxing the Key Assumptions}

Efficiency disappears under alternate assumptions. Consider first a different bridge financing arrangement, under which zone governments rely on local tax revenue to pay for 
bridge capacity, which is then used by outsiders free of charge. In this case, the user fee $B\left(k_{m}\right) /\left(n_{s}+n_{m}\right)$ is replaced by a midcity head tax of $B\left(k_{m}\right) / n_{m}$ in (12) and by zero in (13), indicating free use of the midcity bridge by suburban residents. The first-order condition for decentralized choice of $k_{m}$ becomes

$$
\frac{B^{\prime}\left(k_{m}\right)}{n_{m}}+T_{2}\left(n_{s}+n_{m}, k_{m}\right)=0
$$

which differs from the optimality condition (7). The absence of cost sharing, which reduces the factor dividing $B^{\prime}\left(k_{m}\right)$ and thus raises the per capita cost of bridge expansion, inefficiently reduces the incentive of midcity residents to do so. Analysis that is available on request shows that the overall impact of this different financing scheme is ambiguous. But if $V^{\prime \prime}$ is close to zero, indicating high price sensitivity of the demand for land, then the new financing scheme leads to a smaller $k_{m}$, an outcome that conforms to intuition. In addition, population shifts from the midcity to the central zone as some commuters seek to avoid the smaller midcity bridge, with $n_{c}$ rising and $n_{m}$ falling relative to the previous efficient equilibrium $\left(q_{c}\right.$ and $q_{m}$ move in directions opposite to the zone populations). However, the change in $n_{s}$, and thus in the city's overall spatial size, remains ambiguous. ${ }^{6}$

Suppose instead that user-fee financing is retained but that bridge capacity is produced with nonconstant returns. Then, toll revenue no longer equals the cost of optimal capacity, and budget-balancing user-fees will not coincide with optimal congestion tolls, yielding an inefficient equilibrium. To see this conclusion, suppose that capacity costs are given by $\beta k^{\alpha}$, with $\alpha \neq 1$. Then $B^{\prime}$ in the capacity condition (7) is replaced by $\alpha \beta k_{m}^{\alpha-1}$. With $\left(n_{s}+n_{m}\right) T_{2}$ again equal to $-\left[\left(n_{s}+n_{m}\right)^{2} / k_{m}\right] T_{1}$, rearrangement of $(7)$ yields

$$
\left(n_{s}+n_{m}\right) T_{1}^{m}=\frac{\alpha \beta k_{m}^{\alpha}}{n_{s}+n_{m}}=\alpha \frac{B\left(k_{m}\right)}{n_{s}+n_{m}}
$$

Substitution in (10) then yields a condition that is no longer the same as the equilibrium condition (18), a consequence of the new $\alpha$ factor. This conclusion also applies to (11) and

\footnotetext{
${ }^{6}$ Note that $q_{s}$ (which is tied to $\bar{r}$ ) and $n_{s} / k_{s}$ remain constant, being unaffected by the financing used for the midcity bridge.
} 
(19). The equilibrium is thus inefficient, but the directions in which the variables diverge from the optimum is mostly ambiguous, although a few comparisons can be derived for special cases.

\section{Centralized Decisions}

While decentralized capacity choices are efficient under the conditions of Proposition 1, it is illuminating to consider the centralized case, where a single city government sets capacities and fees on both bridges, under these same conditions. Before characterizing choices in this case, let $T\left(n_{s}+n_{m}, k_{m}\right)$ be written as $t\left[\left(n_{s}+n_{m}\right) / k_{m}\right]$ using the zero-degree homogeneity assumption, where $t^{\prime}>0\left(T^{s}\right.$ similarly becomes $\left.t\left(n_{s} / k_{s}\right)\right)$. Then, (16) and (17) reduce to

$$
\frac{\beta k_{s}}{n_{s}}=t^{\prime}\left(\frac{n_{s}}{k_{s}}\right) \frac{n_{s}}{k_{s}}, \quad \frac{\beta k_{m}}{n_{s}+n_{m}}=t^{\prime}\left(\frac{n_{s}+n_{m}}{k_{m}}\right) \frac{n_{s}+n_{m}}{k_{s}} .
$$

Given the common form of these conditions, it follows that the volume/capacity ratios $\left(n_{s}+\right.$ $\left.n_{m}\right) / k_{m} \equiv R_{m}$ and $n_{s} / k_{s} \equiv R_{s}$ on the midcity and suburban bridges are the same in the decentralized equilibrium, taking a common value denoted $R^{*}$. Congestion levels and user fees are then also equalized.

The equal-congestion condition could be imposed as a horizontal-equity requirement in centralized decisions, with volume/capacity ratios on both bridges required to equal some common value $R$. If equal user fees were also required, ruling out cross-subsidies between bridges, the fees would equal $\beta / R$ on both bridges. Transport costs would then be $(\beta / R)+$ $t(R)$ for midcity residents and twice this value for suburban residents, leading both groups to prefer a common $R$ equal to $R^{*}$. With central residents indifferent to $R$ 's value, all the city's residents would then unanimously support choice of $R^{*}$, implying that the efficient, decentralized outcome is achieved under centralization. Summarizing yields

Proposition 2. If horizontal equity is required, with both congestion levels and user fees constrained to be equal across bridges, then centralized choice replicates the efficient decentralized equilibrium.

By contrast, suppose that a uniform user fee $\tau$ that balances the central budget were required under centralization, but that bridge congestion levels were allowed to differ. The 
user fee would then satisfy $\left(2 n_{s}+n_{m}\right) \tau=\beta\left(k_{s}+k_{m}\right)$. Midcity and suburban total userfee payments would then be $\beta\left(k_{s}+k_{m}\right) /\left(2 n_{s}+n_{m}\right)$ and double this amount, respectively. Substituting these values into (12) and (13), it is easy to see that residents of two zones would have different preferred values of $k_{s}$ and $k_{m}$. These preferences would have to be aggregated in some fashion in a centralized decision process, whose outcome is bound to be inefficient.

\section{Conclusion}

This paper has shown that the inefficiency of fiscal decentralization in the presence of spillovers, a main tenet of the decentralization literature, is overturned in a particular transportation context. In a monocentric city where road (bridge) capacity is financed by budgetbalancing user fees, decentralized capacity choices (made by individual zones within the city) generate the social optimum despite the presence of spillovers. This conclusion, which is closely tied to the famous self-financing theorem of transporation economics, provides a notable counterpoint to received wisdom on fiscal decentralization. 


\section{References}

Anas, A., Pines, D., 2008. Anti-sprawl policies in a system of congested cities. Regional Science and Urban Economics 38, 408-423.

Besley, T., Coate, S., 2003. Centralized vs. decentralized provision of local public goods: A political economy analysis. Journal of Public Economics 87, 2611-2637.

Brueckner, J.K., Helsley, R.W., 2011. Sprawl and blight. Journal of Urban Economics 69, 205-213.

DeBorger, B., Proost, S., 2013. The political economy of centralizing and decentralizing congestible local public goods. Unpublished paper, University of Antwerp.

Ferguson, G., 2013. Transportation-system choice in a fragmented metropolis. Unpublished paper, UC Irvine.

Kanemoto, Y., 1977. Cost-benefit analysis and the second best land use for transportation. Journal of Urban Economics 4, 483-503.

OAtes, W.E., 1972. Fiscal Federalism. Harcourt Brace, New York.

Pines, D., SADKA, E., 1985. Zoning, first-best, second-best and third-best criteria for allocating land for roads. Journal of Urban Economics 17, 167-183.

Small, K.A., Verhoef, E.T., 2007. The Economics of Urban Transporation. Routledge, Abington, UK.

Westin, J., Franklin, J.P., Grahn-Voorneveld, S., Proost, S., 2012. How to decide on regional infrastructure to achieve intra-regional acceptability and inter-regional consensus? Papers in Regional Science 91, 617-643.

Wheaton, W.C., 1998. Land use and density in cities with congestion. Journal of Urban Economics 43, 258-272.

Ogawa, H., Wildasin, D.E., 2009. Think locally, act locally: Spillovers, spillbacks, and efficient decentralized Policymaking. American Economic Review 99, 1206-1217. 


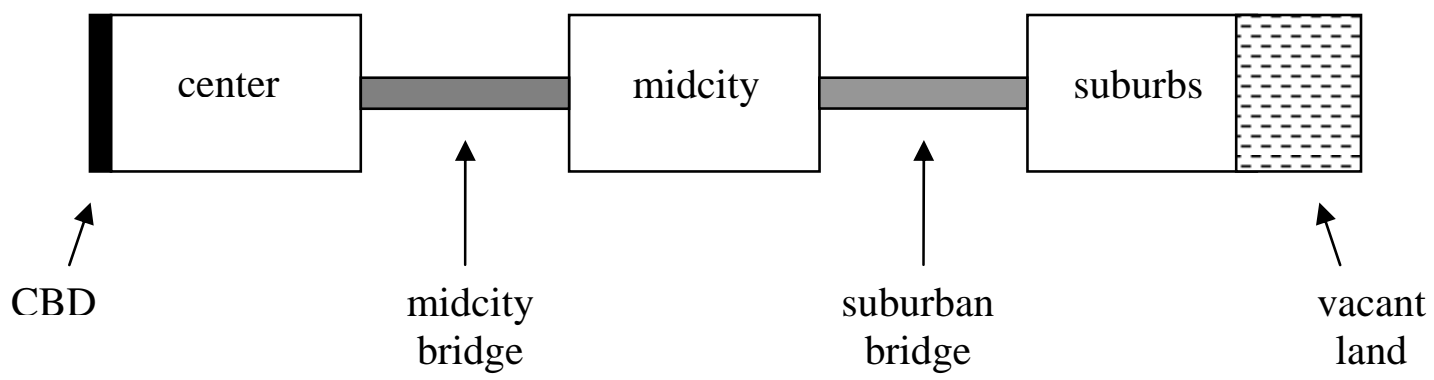

Figure 1: City map 